\title{
Degree of Viremia and Liver Histology in Chronic Hepatitis C
}

\author{
*Md Atiqur Rahman ${ }^{1}$, Sultana Rokeya Mannan ${ }^{2}$ \\ ${ }^{1}$ Dr. Md Atiqur Rahman, Lecturer, Community Medicine \\ Anwer Khan Modern Medical College, Dhanmondi, Dhaka \\ ${ }^{2}$ Dr. Sultana Rokeya Manna, Associate Professor, Physiology, \\ Anwer Khan Modern Medical College, Dhanmondi, Dhaka \\ *Corresponding Author
}

\begin{abstract}
This non-interventional descriptive study, was carried out in a private centre named The Liver Centre, Dhanmondi, Dhaka, between April and September, 2010. Core needle liver biopsies of fifty five patients of chronic hepatitis $\mathrm{C}$ were evaluated according to Knodell's histological activity index system. The patients were categorized into four subgroups depending upon the grade and stage of disease according to Desmet's classification, and into three groups according to degree of viremia. Five patients had mild viremia, 43 moderate and 7 had severe viremia. Seven patients had minimal disease, 9 mild, 22 moderate and 17 had severe chronic hepatitis. Eight patients had no fibrosis, 20 had fibrous portal expansion, 19 bridging fibrosis, and 8 patients had cirrhosis. No significant correlation was found between serum HCV RNA levels and grade or stage of the disease, with correlation coefficients of rs $=-.054$ and $\mathrm{rs}=$ .034 respectively. Moreover, no individual component of the HAI correlated with serum HCV RNA levels. Serum HCV RNA level does not determine the degree of hepatic injury precisely and liver biopsy is necessary to accurately evaluate the extent of liver damage.
\end{abstract}

Key Words: HCV, Chronic Hepatitis, Liver Biopsy

\section{Introduction}

Hepatitis $\mathrm{C}$ is a global disease with worldwide prevalence estimated to be around 3\%. ${ }^{1}$ Due to the paucity of authentic epidemiological studies in Bangladesh, it is difficult to comment on the exact prevalence of $\mathrm{HCV}$ infection in our country. In healthy blood donors, the prevalence varies from 0 to $29.89 \%$ and in general population from 4 to $25.7 \%{ }^{2}$.

Liver biopsy and histological evaluation are considered to be the gold standard, to determine the degree of liver injury in chronic hepatitis $\mathrm{C}^{3}$. In an attempt to standardize the histological evaluation of chronic hepatitis, Knodell et al ${ }^{4}$. In 1981 described a semi quantitative method of scoring liver biopsies that scores four different sets of histological features: Periportal necrosis with or without bridging necrosis, portal inflammation, intralobular degeneration and necrosis, and hepatic fibrosis. The first three features with a score of 0 to 18 , evaluate the necroinflammatory component of the disease and therefore are a measure of histological activity or grade of the disease. The fourth component, fibrosis, with a score of 0 to 4 evaluates the histological stage of the disease. The summation of individual component scores provides a total histological activity index (HAI) with a score of 0 to 22 .

Although liver biopsy is a safe procedure in experienced hands, the risk of complications is still about $3 \%{ }^{5}$. Most of these complications are mild like pain and bleeding, but severe complications like pneumothorax and septic shock, have generated a need to evaluate whether non invasive tests such as serum ALT and HCV RNA estimation, can adequately predict the degree of hepatic damage, to be used as alternate tests for liver biopsy.

The purpose of this study was to determine the degree of viremia and histological liver damage 
and serum HCV RNA level, in our setup, to evaluate whether HCV RNA estimation can replace liver biopsy in management of chronic hepatitis $\mathrm{C}$.

\section{Materials and Methods}

A non-interventional descriptive study carried out in a private centre named The Liver Centre, Dhanmondi, Dhaka, between April and September 2010. A total of fifty five patients of chronic hepatitis $\mathrm{C}$ were included in this study. The sampling technique was convenient nonprobability. Patients of all ages and both sexes, whose serum HCV RNA estimation had been carried out in different well known diagnostic centre located Dhaka city, with exception of those having a coexisting liver disease which could alter the state of liver damage, including: chronic hepatitis B, Wilson's disease, hemochromatosis, alcoholic liver disease and autoimmune hepatitis. Patients who had previously received antiviral therapy were also excluded from the study.

\section{Data Collection Procedure}

Histological evaluation was done on formalin fixed, paraffin embedded sections of core needle liver biopsies, stained with hematoxylin and eosin. Reticulin stain was also used in routine for evaluation of fibrosis. Knodell's HAI system ${ }^{4}$ was used to evaluate separate scores for amount of periportal and bridging necrosis (0-10), intralobular degeneration and necrosis $(0-4)$, portal inflammation (0-4), and hepatic fibrosis (0-4), with a total score of $0-22$. According to Desmet's classification ${ }^{6}$ patients were placed in four groups depending upon the grade of the disease (0-18):
a. Minimal
chronic
hepatitis $\mathrm{C}$
b. Mild
chronic
hepatitis $\mathrm{C}$
hepatitis $\mathrm{C}$
c. Moderate
chronic
hepatitis $\mathrm{C}$
d. Severe
chronic
(13-18)

And four groups according to the stage of the disease (0-4)
a. No
fibrosis
b. Fibrous
portal
expansion
c. Bridging
fibrosis
d. Cirrhosis

(0)
The patients were placed in three groups according to serum HCV RNA level, estimated by Polymerase chain reaction (PCR) :
a. Mild
viremia
$<10^{6}$
copies $/ \mathrm{ml}$
b. Moderate
viremia
$10^{6}-10^{8}$
copies $/ \mathrm{ml}$
c. Severe
viremia
$>10^{8}$
copies $/ \mathrm{ml}$

The correlation of various grades and stages of liver damage with degree of hepatitis $\mathrm{C}$ viremia was assessed by calculation of Spearman rank correlation coefficients, using the software programme SPSS version 10 .

\section{Results}

The age of the patients ranged between 17 to 50 years with a mean age of 32.5 years. Most of the patients were in the third and fourth decades. The male to female ratio was $2: 1$. Majority $(40 \%)$ of the patients had moderate disease, followed by severe hepatitis. Twenty $(36.4 \%)$ patients had fibrous portal expansion, with almost similar number having bridging fibrosis (Table I). Out of 55 patients, 5 had mild viremia, 43 moderate and 7 had severe viremia.

Table I: Grade and Stage of Hepatic disease $(\mathrm{n}=55)$

\begin{tabular}{|c|c|c|c|}
\hline Grade & $\begin{array}{l}\text { Frequency } \\
(\%)\end{array}$ & Stage & $\begin{array}{l}\text { Frequency } \\
\text { (\%) }\end{array}$ \\
\hline Minimal & $7(12.7)$ & No fibrosis & $8(14.5)$ \\
\hline Mild & $9(16.4)$ & $\begin{array}{l}\text { Fibrous Portal } \\
\text { Expansion }\end{array}$ & $20(36.5)$ \\
\hline Moderate & $22(40.0)$ & Bridging Fibrosis & $19(34.5)$ \\
\hline Severe & $17(13.9)$ & Cirrhosis & $8(14.5)$ \\
\hline
\end{tabular}

Table II: Correlation between Viremia vs Grade \& Stage of Liver disease

\begin{tabular}{ll}
\hline rs value & \\
\hline Grade & -.054 \\
Viremia & \\
Stage & 0.034 \\
Viremia & \\
\hline
\end{tabular}

\section{Level of Viremia vs Grade of disease}

Table II clearly shows that there is no relationship between grade of the disease and level of viremia, as one patient with mild viremia had severe chronic hepatitis and one patient with severe viremia had minimal hepatitis. Moreover, there is no relationship of other sets of grades of liver disease with level of viremia. 
Calculation of the Spearman rank correlation coefficients revealed Spearman rho ( rs ) $=-0.054$ for Viremia vs Grade. Value of the correlation coefficient being very near to zero, shows that no significant correlation exists between level of viremia and grade of liver disease.

\section{Level of Viremia vs Stage of disease}

Likewise, no relationship could be seen between level of viremia and stage of the disease (Table II), since 6 patients with moderate viremia had no fibrosis, while only one patient with severe viremia had cirrhosis. The Spearman rho of 0.034 for Viremia vs Stage showed no significant correlation between the two variables.

\section{Correlation of level of viremia with individual components of $\mathrm{HAI}$}

The coefficients of correlation between level of viremia and portal inflammation, intralobular degeneration and necrosis, and periportal necrosis were also calculated and the values of all three $(0.033,0.021$ and 0.005 respectively) were indicative of a lack of significant correlation.

\section{Discussion}

Hepatitis $\mathrm{C}$ has an alarmingly high rate of developing chronicity and there is no vaccine available, due to marked genomic variation in the virus. Treatment with interferon a as a single agent or in combination with ribavirin, has shown promising results in a large number of patients ${ }^{7,8}$. Liver biopsy forms the backbone of the current protocol $^{9,10}$ for initiation of antiviral treatment. Presence of moderate or severe necroinflammation, and fibrous portal expansion or bridging fibrosis, along with persistently elevated ALT and positive HCV RNA, are the indications for initiation of treatment and presence of cirrhosis is a relative contraindication. Similarly, in patients with no fibrosis and minimal necro-inflammation, observation with 6 monthly serial estimation of serum ALT and liver biopsy every 3-4 years is recommended.

Due to the complications and expense of liver biopsy there has been a considerable enthusiasm to search for alternate, non-invasive tests like serum ALT or HCV RNA estimation. Numerous studies have shown a poor correlation between serum ALT levels and histological activity ${ }^{11-13}$. Therefore there is little role of serum ALT estimation as an alternate for liver biopsy. But the interest in the role of serum HCV RNA estimation has been kept alive by a few studies, which show a linear relationship between degree of liver injury and level of viremia ${ }^{14,15}$. However most of the studies done on this subject, around the world, have shown no significant correlation between the two ${ }^{16-21}$.

This study like others found no correlation between level of viremia and grade or stage of liver disease, as well as with individual components of $\mathrm{HAI}^{19,21}$. We therefore conclude that serum HCV RNA level does not determine the degree of hepatic damage precisely, and although it has an important role in the management of chronic hepatitis $\mathrm{C}$, it cannot be used as an alternate to liver biopsy.

\section{References}

1. Pradat P, Trepo C. HCV: epidemiology, modes of transmission and prevention of spread. Baillieres Best Pract Res Clin Gastroenterol 2000; 14: 201-10.

2. Shah NH, Shabbir G. A review of published literature on hepatitis B and $\mathrm{C}$ virus prevalence in Pakistan. $J$ Coll Physicians Surg Pak 2002; 12: 368-71.

3. McCormick SE, Goodman ZD, Maydonovitch CL, et al. Evaluation of liver histology, ALT elevation, and HCV RNA titer in patients with chronic hepatitis C. Am J Gastroenterol 1996; 91: 1516-22.

4. Knodell RG, Ishak KG, Black WC, et al. Formulation and application of a numerical scoring system for assessing histological activity in asymptomatic chronic active hepatitis. Hepatology 1981; 431-5.

5. Perrault J, McGill DB, Ott BJ, et al. Liver biopsy: complications in 1000 inpatients and outpatients. Gastroenterology 1978; 74: 103-6.

6. Khokhar N. Effectiveness of 48 weeks Interferon alfa-2b in combination with ribavirin as initial treatment of chronic hepatitis. J Ayub Med Coll Abbottabad 2002; 14: 5-8.

7. McHutchison JG, Gordon SC, Schiff ER, et al. Interferon alfa- $2 b$ alone or in combination with ribavirin as initial treatment for chronic hepatitis C. Hepatitis Interventional Therapy Group. N Engl J Med 1998; 339: 1485-92. 
8. Foster GR, Thomas HC. Therapeutic options for HCVmanagement of the infected individual. Baillieres Best Pract Res Clin Gastroenterol 2000; 14: 255-64.

9. Collier J, Chapman R. Combination therapy with interferon-alpha and ribavirin for hepatitis $\mathrm{C}$ : practical treatment issues. Bio Drugs 2001; 15: 225-38.

10. Persico M, Romano $M$. Alanine aminotransferase measurements and histological disease in hepatitis C. Lancet 1993; 342: 1369-70.

11. Morales TJ, Samplier RE, Bhattacharyya A. Liver histology in individuals with positive markers for HCV and normal or minimally elevated aminotransferases. Am J Gastroenterol 1994; 47: 1674-8.

12. Puoti C, Magrini A, Stati T, et al. Clinical, histological, and virological features of hepatitis $\mathrm{C}$ virus carriers with persistently normal or abnormal alanine transaminase levels. Hepatology 1997; 26: 1393-8.

13. Choi Y, Putti T, Win K, et al. Correlation of viral RNA, alanine aminotransferase, and histopathology in hepatitis C virus-associated hepatitis. Mol Diagn 1999; 4: 251-4.

14. Adinolfi LE, Utili R, Andreana A, et al. Serum HCV RNA levels correlate with histological liver damage and concur with steatosis in progression of chronic hepatitis C. Dig Dis Sci 2001; 46: 1677-83.
15. Puoti C, Stati T, Magrini A. Serum HCV RNA titer does not predict the severity of liver damage in HCV carriers with normal aminotransferase levels. Liver 1999; 19: 104-9.

16. Romeo R, Colombo M, Rumi $\mathrm{M}$, et al. Lack of association between type of hepatitis $\mathrm{C}$ virus, serum load and severity of liver disease. J Viral Hepat 1996; 3: 183-90.

17. Bernardi M, Glauser A, Kupferschmidt H, et al. Virus titre and histological inflammation activity in chronic hepatitis C. Schweiz Med Wochenschr Suppl 1996; 79: 30-5.

18. McCormick SE, Goodman ZD, Maydonovitch CL, et al. Evaluation of liver histology, ALT elevation, and HCV RNA titer in patients with chronic hepatitis C. Am J Gastrenterol 1996; 91: 1516-22.

19. Lee YS, Yoon SK, Chung ES, et al. J Korean Med Sci 2001; 16: 585-91.

20. Luo JC, Hwang SJ, Lai CR, et al. Relationship between serum aminotransferase levels, liver histologies and virological status in patients with chronic hepatitis $\mathrm{C}$ in Taiwan. J Gastroenterol Hepatol 1998; 13: 685-90.

21. De Moliner L, Pontisso P, De Salvo GL, et al. Serum and liver HCV RNA levels in patients with chronic hepatitis $\mathrm{C}$ : correlation with clinical and histological features. Gut 1998; 42: 856-60. 